\title{
Estudio y análisis de la evolución de los estudiantes matriculados en titulaciones de Educación Musical en la Universidad Autónoma de Madrid
}

Study and Analysis of the Evolution of Students Enrolled in Music Education Degrees at the Universidad Autónoma de Madrid

María Elena Cuenca Rodríguez maria.cuenca@uam.es Departamento de Música Universidad Autónoma de Madrid Madrid, España ORCID: http://orcid.org/0000-0002-5419-2576

Miren Pérez Eizaguirre miren.perez@uam.es

Departamento de Música

Universidad Autónoma de Madrid

Madrid, España

ORCID: https://orcid.org/0000-0003-0959-6907

$\begin{array}{r}\text { Ángela Morales Fernández } \\ \text { angela.morales@uam.es }\end{array}$
$\begin{array}{r}\text { Departamento de Música } \\ \text { ORCID: https://orcid.org/0000-0002-9839-5877 }\end{array}$

doi: 10.7203/LEEME.47.18295

Recibido: 22-09-2020 Aceptado: 21-12-2020. Contacto y correspondencia: María Elena Cuenca Rodríguez, Departamento de Música, Universidad Autónoma de Madrid, Facultad de Formación del Profesorado y Educación, C/Francisco Tomás y Valiente, 3, C.P. 28049 Madrid. España.

Resumen

Este artículo muestra una investigación descriptiva y analítica de datos institucionales a lo largo del tiempo. Los objetivos planteados se circunscriben a la descripción de la evolución de la antigua especialidad de Música en la Facultad de Formación de Profesorado de la Universidad Autónoma de Madrid, así como a los factores determinantes de esta evolución en la pérdida tanto cualitativa, desde el punto de vista curricular, como cuantitativa en lo que respecta al cómputo en créditos/horas con la aparición de las menciones. Por otra parte, se referencia el lugar que ocupa la Mención de Educación Musical en el conjunto de menciones de la citada Facultad, tanto para el Grado de Maestro de Primaria como de Infantil. Los resultados evidencian de forma definida el concepto de maestro especialista frente al de maestro generalista en la evolución legislativa. Por otra parte, la conclusión más notable es que, con las nuevas menciones, la Educación Musical, ha perdido de forma relevante un espacio formativo para la Educación Musical en la Educación Infantil y Primaria, considerando las cifras de estudiantes de nuevo ingreso y comparándolas con las de la antigua Diplomatura de la Especialidad de Música y las de las demás menciones ofertadas actualmente.

Palabras clave: Educación Musical; formación de profesorado; especialización; título universitario.

\section{Abstract}

This article shows a descriptive and analytical investigation of institutional data over time. The proposed objectives are limited to the description of the evolution of the old specialty of Music in the Facultad de Formación de Profesorado de la Universidad Autónoma de Madrid, as well as the determining factors of this evolution in both qualitative loss, from the curricular point of view, as quantitative in regards to the computation in credits / hours with the arrival of the specializations. On the other hand, the place that the specialization of Musical Education occupies on the whole of the remaining specializations is referenced, both for the Primary and Infant Education degrees. The results clearly show the concept of a specialist teacher against that of a general teacher in legislative evolution. On the other hand, the most notable conclusion is that Music Education has significantly lost a formative space for Music Education in Early Childhood and Primary Education with the new mentions, considering the numbers of new students and comparing them with those of the former Music Specialty degree and those of the other mentions currently offered.

Key words: Music Education; Teacher Education; Specialization; Academic Degree.

@ María Elena Cuenca Rodríguez, Miren Pérez Eizaguirre y Ángela Morales Fernández. The content of this article is the sole responsibility of the authors. The Revista Electrónica de LEEME and Universitat de València are not liable for any legal actions that may arise involving the article's content. Revista Electrónica de LEEME - Lista Electrónica Europea de Música en la Educación-. http://ojs.uv.es/index/php/LEEME/index ISSN: 1575-9563. Editores: Universidad de Valencia y Jesús Tejada. Visibilidad de esta revista: SCOPUS, Emerging Sources Citation Index (Clarivate), EBSCO, CINDOC (CSIC), Citefactor, COPAC, Dialnet, DICE (CSIC), DOAJ, e-revistas (CSIC), EBSCO Premier, ERIH+, Gale Cengage Learning, IN-RECS, IRESIE, LATINDEX, MIAR, OCLC Worldcat, RESH, REDIB, RILM Core Journals, SUDOC, ULRICHS. Esta revista es de acceso libre mediante licencia Creative Commons 4.0 CC by. Política de archivado: etiqueta verde SHERPA-ROMEO. 


\section{Introducción}

La especialidad de Educación Musical en la formación del profesorado ha sufrido numerosos y profundos cambios en las últimas décadas. El aspecto más notable es cómo ha afectado a la formación del alumnado universitario, que en un inicio estudiaba la música como una especialidad, al pasar posteriormente a una mención cualificadora. Para describir este proceso realizado por otros autores (Belletich y Wilhelmi, 2017; Casanova y Serrano, 2018; López García, Madrid y de Moya Martínez, 2017), se llevará a cabo un análisis de esta evolución en el estudiantado de la especialidad y la Mención en Educación Musical de la Facultad de Educación y Formación del Profesorado de la Universidad Autónoma de Madrid.

\subsection{La LOGSE y la nueva especialidad de maestro en Educación Musical}

La Ley Orgánica 1/1990, de 3 de octubre, de Ordenación General del Sistema Educativo (LOGSE) estableció un nuevo modelo educativo que sustituyó a la reforma de la Ley 14/1970, de 4 de agosto, General de Educación y Financiamiento de la Reforma Educativa (LGE) y a la Ley Orgánica 8/1985, de 3 de julio, reguladora del Derecho a la Educación(LODE). Aunque la LGE ya contemplaba la música como parte del currículo de la educación general, la aparición de la LOGSE supuso un avance muy importante en el entorno educativo musical, incluyendo esta disciplina como área de conocimiento en el currículo de la educación obligatoria (Touriñán y Longueira, 2010), así como reestructurando las enseñanzas de carácter especial (Escuelas y Conservatorios de Música y Danza). Esto supuso la aparición inmediata del especialista en Educación Musical para la Educación Primaria como nuevo miembro del equipo docente.

En esta línea, Reyes (2010) hace una síntesis del perfil profesional del alumnado que cursaba el plan antiguo y marca las competencias que debía lograr: específicas, relacionadas con los ámbitos cognitivo, procedimental y actitudinal. Según la autora, no existía ninguna prueba específica de acceso a ninguno de los planes de Magisterio de la especialidad de Música, lo que supuso que no se necesitaran conocimientos técnico-musicales previos más allá de los que se impartían en la educación obligatoria. Para Montesinos (2011), una buena formación musical inicial del profesorado junto a la experiencia docente son la base de la calidad de la Educación Musical escolar.

\subsection{El Plan Bolonia. La Mención en Educación Musical}

Son muchos los nombres que el alumnado universitario español utiliza para referirse a los nuevos tiempos que les ha tocado vivir en este nuevo reto formativo que se denomina Espacio Europeo de Educación Superior. El nombre más habitual es "Proceso Bolonia". Dicho proceso 

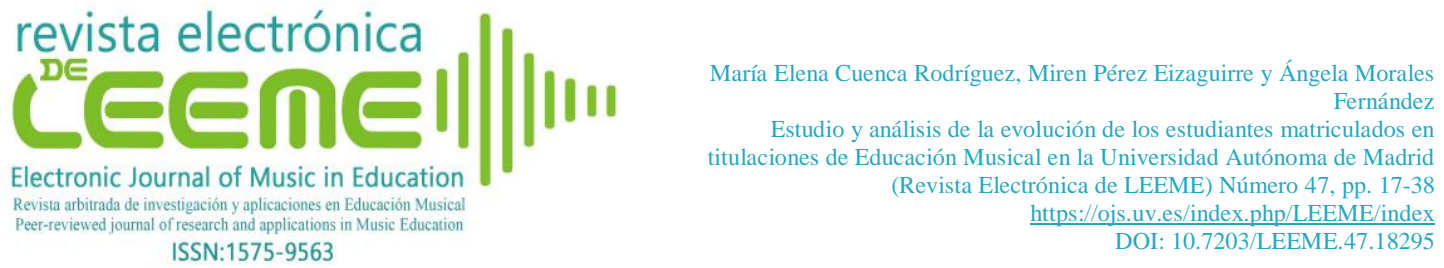

recibe el nombre del acuerdo que el 19 de junio de 1999 los ministros de educación de diferentes países firmaron en una declaración conjunta, La Declaración de Bolonia (Italia), que sentó las bases de un proceso de convergencia y unificación en cuanto a las titulaciones universitarias y creando así el Espacio Europeo de Educación Superior (EEES), que se implementaría en España en el año 2010 (Montero, 2010).

Uno de los cambios más significativos fue la adopción del Sistema Europeo de Transferencia y Acumulación de Créditos (European Credit Transfer and Accumulation SystemECTS). En el nuevo sistema de créditos, la actividad dedicada a las horas de trabajo por parte del discente (entre 25 y 30 horas por crédito) incorpora el tiempo dedicado a las horas de estudio, horas lectivas, tutorías, seminarios, prácticas, trabajos o proyectos, además de las horas que se necesiten para la preparación y realización de exámenes y evaluaciones (López García, 2015). La Ley Orgánica 2/2006, de 3 de mayo, de Educación (LOE) mantuvo la Educación Musical en estos mismos tramos educativos (enseñanzas generales y enseñanzas especiales) y planteó el compromiso decidido con los objetivos educativos trazados por la Unión Europea en la consecución de una enseñanza de calidad. El 27 de diciembre de 2007 se publicaron dos órdenes por las que se establecieron los requisitos para la verificación de los títulos universitarios oficiales de Grado que habilitarían para el ejercicio de la profesión de Maestro en Educación Infantil y Maestro en Educación Primaria, donde se propone el planteamiento en créditos de las menciones cualificadoras ${ }^{1}$.

Diversas investigaciones realizaron una prospección de lo que supondría el Plan Bolonia (Baena, 2007; Rodríguez, Navarro y Rojo, 2010; Maldonado, 2004), especificando alguno de ellos el papel de la música en la escuela tras este proceso (Díaz, 2005). De manera más concreta, Esteve et al. (2006) y Ocaña (2006) señalaron la falta de unos requisitos previos a la hora de estudiar la Mención en Educación Musical, lo que ha supuesto la dificultad del discente para obtener una competencia musical suficiente que le permitiera que cada egresado impartiera música con garantías en los centros de Educación Primaria, que es, precisamente, una de las mayores dificultades del profesorado de la titulación. Otros concluyen que "la propuesta que surge de dicho proceso de la formación de un profesorado generalista responsable de las enseñanzas musicales en la escuela, tal y como está siendo promovido, supone un retroceso con respecto a la situación actual" (Aróstegui, 2006, p.829).

Las nuevas directrices educativas definidas en la actual Ley Orgánica 8/2013, de 9 de diciembre, para la mejora de la calidad educativa (LOMCE) cambiaron radicalmente la situación

\footnotetext{
${ }^{1} \mathrm{La}$ Orden ECI/3857/2007, de 27 de diciembre, por la que se establecen los requisitos para la verificación de los títulos universitarios oficiales que habiliten para el ejercicio de la profesión de Maestro en Educación Primaria y la Orden ECI/3854/2007, de 27 de diciembre, por la que se establecen los requisitos para la verificación de los títulos universitarios oficiales que habiliten para el ejercicio de la profesión de Maestro en Educación Infantil.
}

@ María Elena Cuenca Rodríguez, Miren Pérez Eizaguirre y Ángela Morales Fernández. The content of this article is the sole responsibility of the authors. The Revista Electrónica de LEEME and Universitat de València are not liable for any legal actions that may arise involving the article's content. Revista Electrónica de LEEME - Lista Electrónica Europea de Música en la Educación-. http://ojs.uv.es/index/php/LEEME/index ISSN: 1575-9563. Editores: Universidad de Valencia y Jesús Tejada. Visibilidad de esta revista: SCOPUS, Emerging Sources Citation Index (Clarivate), EBSCO, CINDOC (CSIC), Citefactor, COPAC, Dialnet, DICE (CSIC), DOAJ, e-revistas (CSIC), EBSCO Premier, ERIH+, Gale Cengage Learning, IN-RECS, IRESIE, LATINDEX, MIAR, OCLC Worldcat, RESH, REDIB, RILM Core Journals, SUDOC, ULRICHS. Esta revista es de acceso libre mediante licencia Creative Commons 4.0 CC by. Política de archivado: etiqueta verde SHERPA-ROMEO. 
de la Educación Musical en la etapa de Primaria. Ya afirmaba Carbajo (2009) que una de las consecuencias de este cambio en el perfil profesional del profesorado de Educación Primaria era que, en los colegios, aparecerían tres tipos diferentes de docentes (generalista, especializado y profesionales de la Música con la debida preparación pedagógica), en función del grado de preparación musical que tuvieran con anterioridad. En esta línea, existen diferentes visiones entre los que abogaron por la existencia del profesorado especialista (Montesinos, 2011) en contraposición a la defensa del generalista con una buena formación específica (Aróstegui, 2006; Aróstegui, 2013; Aróstegui, y Cisneros-Cohernour, 2010;).

Asignar la docencia del área de Música al profesorado generalista o a un especialista responde a la resolución del conflicto que se produce en la toma de la decisión acerca de otorgar más o menos peso específico a las capacidades personales en música. Asimismo, Aróstegui, Louro y de Oliveira (2015) exponen que el neoliberalismo y sus implicaciones se ven reflejadas en estas políticas de reforma y proponen algunas acciones que los educadores musicales podrían llevar a cabo para intentar paliar en lo posible esta situación como dar respuestas a los retos educativos y sociales y no considerar la música desde una visión romántica.

Tras esta introducción, se exponen los objetivos planteados para esta investigación:

- Describir cómo ha sido la evolución de la presencia de los estudios pedagógicos de Música desde la implantación de la política europea (EESS) en la Facultad de Educación y Formación del Profesorado de la Universidad Autónoma de Madrid.

- $\quad$ Establecer qué factores han sido determinantes y han influido en el tránsito de los diferentes planes.

- $\quad$ Ubicar la Mención en Educación Musical entre las diferentes menciones que se han ofertado en la Facultad de Formación del Profesorado y Educación de la Universidad Autónoma de Madrid.

\section{Método}

Se ha llevado a cabo una investigación de tipo descriptivo y analítico en el que se detalla la evolución de los estudios de Música en la Facultad de Formación del Profesorado y Educación de la Universidad Autónoma de Madrid. Se ha realizado un recorrido sobre el plan de estudios en los dos momentos señalados anteriormente (1991-2007), la especialidad de Música y la Mención en Educación Musical en los Grados de Maestro en Educación Infantil y Educación Primaria, respectivamente. Asimismo, se ha analizado el número de estudiantes matriculados en ambos casos. Los datos que se aportan son los ofrecidos directamente por la propia Universidad 
Autónoma de Madrid en el portal de anuarios completos (Universidad Autónoma de Madrid, 2020).

Los resultados parten directamente del objetivo general de esta: analizar la evolución del alumnado matriculado en la Mención en Educación Musical de los Grados de Maestro en Educación Infantil y Primaria en los últimos años, examinando los documentos institucionales de la Facultad de Formación del Profesorado y Educación de la Universidad Autónoma de Madrid.

\section{Resultados}

a) Evolución de la presencia de los estudios pedagógicos en la Facultad de Formación del Profesorado y Educación de la Universidad Autónoma de Madrid

En la Facultad de Formación del Profesorado y Educación de la Universidad Autónoma de Madrid, el número de horas lectivas (presenciales) entre asignaturas troncales y obligatorias que cursaba el alumnado eran las que recoge la Tabla 1, que no tiene en cuenta las materias optativas y de libre configuración específicas de la especialidad.

Tabla 1. Número de créditos plan de estudios de la especialidad de música en la Universidad Autónoma de Madrid

\begin{tabular}{ccccc}
\hline CURSO & $\begin{array}{c}\text { CRÉDITOS } \\
\text { OBLIGATORIOS }\end{array}$ & $\begin{array}{c}\text { CRÉDITOS } \\
\text { OPTATIVOS }\end{array}$ & $\begin{array}{c}\text { CRÉDITOS DE LIBRE } \\
\text { CONFIGURACIÓN }\end{array}$ & Total \\
\hline Primer curso & 63,5 & 4 & 4 & 71,5 \\
Segundo curso & 63 & 4 & 4 & 71 \\
Tercer curso & 47,5 & 3 & 13 & 63,5 \\
\hline
\end{tabular}

Fuente: datos extraídos de la Resolución del 6 de junio de $2020^{2}$ y de Morales (2008, pp.246-249)

En cuanto a la especialidad de Música, se considera conveniente reseñar el plan de estudios completo para esta especialidad, tanto las materias troncales, las obligatorias y las optativas. En el caso de la Facultad de Formación del Profesorado y Educación de la Universidad Autónoma de Madrid, estos créditos se distribuyeron conforme a lo recogido en la Tabla 2.

${ }^{2}$ Resolución, de 6 de junio de 2000, de la Universidad Autónoma de Madrid, por la que se acuerda la publicación de la adaptación del plan de estudios de Maestro, Especialidad de Educación Primaria, homologado por la Comisión Académica del Consejo de Universidades de fecha 21 de julio de 1992. 
Tabla 2. Plan de estudios de la especialidad de música en la Universidad Autónoma de Madrid

\begin{tabular}{|c|c|c|}
\hline $\begin{array}{c}\text { RECORRIDO CURRICULAR } \\
\text { PRIMER CURSO }\end{array}$ & $\begin{array}{l}\text { RECORRIDO CURRICULAR } \\
\text { SEGUNDO CURSO }\end{array}$ & $\begin{array}{c}\text { RECORRIDO CURRICULAR } \\
\text { TERCER CURSO }\end{array}$ \\
\hline $\begin{array}{c}\text { Dificultades del Aprendizaje y } \\
\text { Necesidades Educativas. } \\
\text { TR 4cr. }\end{array}$ & $\begin{array}{l}\text { Psicología de la Educación. } \\
\text { TR } 8 \text { cr. Anual }\end{array}$ & \\
\hline $\begin{array}{c}\text { Psicología del Desarrollo. } \\
\text { TR 4cr. }\end{array}$ & $\begin{array}{l}\text { Didáctica General. } \\
\text { TR } 8 \mathrm{cr} \text {. Anual }\end{array}$ & $\begin{array}{c}\text { Organización del Centro Escolar. } \\
\text { TR. } 4 \text { cr. }\end{array}$ \\
\hline $\begin{array}{c}\text { Teoría de la Acción Educativa. } \\
\text { TR } 4 \mathrm{cr} \text {. }\end{array}$ & $\begin{array}{c}\text { Sociología de la Educación. } \\
\text { TR } 4 \mathrm{cr} \text {. }\end{array}$ & \\
\hline $\begin{array}{c}\text { Nuevas Tecnologías Aplicadas a la } \\
\text { Educación. } \\
\text { TR 4cr. }\end{array}$ & $\begin{array}{c}\text { Didáctica de las Ciencias } \\
\text { Experimentales y Sociales. } \\
\text { TR } 4 \mathrm{cr} \text {. }\end{array}$ & \\
\hline $\begin{array}{c}\text { Matemáticas y su Didáctica. } \\
\text { TR } 8 \mathrm{cr} \text {. Anual }\end{array}$ & $\begin{array}{c}\text { Educación Física y su Didáctica. } \\
\text { TR } 4 \mathrm{cr} \text {. }\end{array}$ & \\
\hline \multirow[t]{2}{*}{$\begin{array}{c}\text { Lengua y Literatura Española y su } \\
\text { Didáctica. } \\
\text { TR } 8 \mathrm{cr} \text {. Anual }\end{array}$} & $\begin{array}{l}\text { Historia del Arte y de la Cultura. } \\
\text { OB. } 4 \mathrm{cr} .\end{array}$ & \\
\hline & $\begin{array}{c}\text { Didáctica de la Expresión Musical } \\
\text { I. } \\
\text { TR 2,5 cr. Anual }\end{array}$ & $\begin{array}{c}\text { Didáctica de la Expresión Musical } \\
\text { II } \\
\text { TR. } 2,5 \mathrm{cr} \text {. }\end{array}$ \\
\hline $\begin{array}{l}\text { Formación Instrumental I. } \\
\text { TR. } 3 \text { cr. Anual }\end{array}$ & $\begin{array}{l}\text { Formación Instrumental II. } \\
\text { TR 3cr. Anual }\end{array}$ & $\begin{array}{l}\text { Formación Instrumental III. } \\
\text { TR. } 2 \mathrm{cr} \text {. }\end{array}$ \\
\hline $\begin{array}{l}\text { Agrupaciones Musicales I. } \\
\text { TR. } 5.5 \mathrm{cr} \text {. Anual }\end{array}$ & $\begin{array}{l}\text { Agrupaciones Musicales II. } \\
\text { TR 2,5 cr. Anual }\end{array}$ & $\begin{array}{c}\text { Agrupaciones Musicales III } \\
\text { TR. } 1,5 \mathrm{cr} \text {. }\end{array}$ \\
\hline $\begin{array}{l}\text { Formación Rítmica y Danza I. TR. } \\
5.5 \mathrm{cr} \text {. Anual }\end{array}$ & $\begin{array}{c}\text { Formación Rítmica y Danza II. } \\
\text { TR 2,5 cr. Anual }\end{array}$ & \\
\hline $\begin{array}{c}\text { Formación Vocal y Auditiva I. } \\
\text { T. 4cr. Anual }\end{array}$ & $\begin{array}{c}\text { Formación Vocal y Auditiva II. } \\
\text { TR 5,5 cr. Anual }\end{array}$ & $\begin{array}{c}\text { Formación Vocal y Auditiva III } \\
\text { TR. } 2,5 \mathrm{cr} \text {. }\end{array}$ \\
\hline $\begin{array}{l}\text { Lenguaje Musical I. } \\
\text { TR. 4cr. Anual }\end{array}$ & $\begin{array}{l}\text { Lenguaje Musical II. } \\
\text { TR 5,5 cr. Anual }\end{array}$ & $\begin{array}{l}\text { Lenguaje Musical III } \\
\text { TR. } 1,5 \mathrm{cr} \text {. }\end{array}$ \\
\hline $\begin{array}{c}\text { Historia de la Música y el Folclore. } \\
\text { TR. 4cr. Anual }\end{array}$ & $\begin{array}{l}\text { Armonía I. } \\
\text { OB. } 5,5 \text { cr. Anual }\end{array}$ & $\begin{array}{l}\text { Armonía II } \\
\text { OB. } 1,5 \mathrm{cr} \text {. }\end{array}$ \\
\hline $\begin{array}{c}\text { Educación Plástica y su Didáctica. } \\
\text { OB. } 5.5 \mathrm{cr} \text {. Anual }\end{array}$ & Análisis. OB. 4 cr. Anual & $\begin{array}{l}\text { Prácticum } \\
\text { TR } 32 \mathrm{cr} \text {. }\end{array}$ \\
\hline
\end{tabular}

Fuente: datos extraídos de la Resolución del 6 de junio de 2020 y de Morales (2008, pp.246-249)³

\footnotetext{
${ }^{3}$ Resolución, de 6 de junio de 2000, de la Universidad Autónoma de Madrid, por la que se acuerda la publicación de la adaptación del plan de estudios de Maestro, Especialidad de Educación Primaria, homologado por la Comisión Académica del Consejo de Universidades de fecha 21 de julio de 1992.
} SCOPUS, Emerging Sources Citation Index (Clarivate), EBSCO, CINDOC (CSIC), Citefactor, COPAC, Dialnet, DICE (CSIC), DOAJ, e-revistas (CSIC), EBSCO Premier, ERIH+, Gale Cengage Learning, IN-RECS, IRESIE, LATINDEX, MIAR, OCLC Worldcat, RESH, REDIB, RILM Core Journals, SUDOC, ULRICHS. Esta revista es de acceso libre mediante licencia Creative Commons 4.0 CC by. Política de archivado: etiqueta verde SHERPA-ROMEO. 


\section{b) La Mención de Educación Musical en la Universidad Autónoma de Madrid. Situación actual}

A continuación, se describe el plan de estudios de las menciones en Educación Musical en los Grados de Educación Infantil y Educación Primaria en la Facultad de Formación del Profesorado y Educación de la Universidad Autónoma de Madrid.

Tabla 3. Descripción de las asignaturas de la Mención en Desarrollo de la Expresión Musical en la Etapa Infantil de la Universidad Autónoma de Madrid

\begin{tabular}{|c|c|c|c|c|}
\hline \multicolumn{5}{|c|}{ MENCIÓN EN DESARROLLO DE LA EXPRESIÓN MUSICAL EN LA ETAPA INFANTIL } \\
\hline ASIGNATURA & CURSO & ECTS & DURACIÓN & TIPO \\
\hline $\begin{array}{c}\text { Didáctica de la } \\
\text { Música y Repertorio } \\
\text { en la Edad Infantil }\end{array}$ & $4^{\circ}$ & 9 & $1^{\circ}$ Semestre & OP \\
\hline Juegos Musicales & $4^{\circ}$ & 6 & $1^{\circ}$ Semestre & OP \\
\hline $\begin{array}{c}\text { Música y } \\
\text { Movimiento }\end{array}$ & $4^{\circ}$ & 6 & $1^{\circ}$ Semestre & OP \\
\hline $\begin{array}{l}\text { Instrumentos } \\
\text { Escolares }\end{array}$ & $4^{\circ}$ & 6 & $1^{\circ}$ Semestre & OP \\
\hline $\begin{array}{c}\text { Recursos } \\
\text { Educativos } \\
\text { Musicales con TIC }\end{array}$ & $4^{\circ}$ & 6 & $1^{\circ}$ Semestre & OP \\
\hline $\begin{array}{c}\text { Prácticum de } \\
\text { Mención en } \\
\text { Educación Musical }\end{array}$ & $4^{\circ}$ & 9 & $2^{\circ}$ Semestre & OB \\
\hline
\end{tabular}

Fuente: datos procedentes de la Resolución de 6 de junio de $2014^{4}$

Tabla 4. Descripción de las asignaturas de la Mención en Educación Musical en el Grado de Educación Primaria de la Universidad Autónoma de Madrid

\begin{tabular}{ccccc}
\hline \multicolumn{4}{c}{ MENCIÓN EN EDUCACIÓN MUSICAL GRADO DE EDUCACIÓN PRIMARIA } \\
ASIGNATURA & CURSO & ECTS & DURACIÓN & TIPO \\
\hline $\begin{array}{c}\text { Formación musical } \\
\text { I: Conjunto }\end{array}$ & $4^{\circ}$ & 9 & $1^{\circ}$ Semestre & OP \\
Instrumental y & & & & \\
Flauta de Pico & & & & \\
Formación Musical & $4^{\circ}$ & 6 & $1^{\circ}$ Semestre & OP \\
II: Formación & & & & \\
Rítmica y Danza & & & &
\end{tabular}

\footnotetext{
${ }^{4}$ Resolución de 6 de junio de 2014, de la Universidad Autónoma de Madrid, por la que se publica la modificación del plan de estudios de Graduado en Magisterio en Educación Infantil.
} 


\begin{tabular}{|c|c|c|c|c|}
\hline $\begin{array}{l}\text { Electronic Journal of I } \\
\text { Revista arbitrada de investigación y ar } \\
\text { Peer-eriewed jounnal of researh and } \\
\text { ISSN:15? }\end{array}$ & $\begin{array}{l}\text { cation } \\
\text { cansical } \\
\text { Education }\end{array}$ & \multicolumn{3}{|c|}{$\begin{array}{r}\text { María Elena Cuenca Rodríguez, Miren Pérez Eizaguirre y Ángela Morales } \\
\text { Fernández } \\
\text { Estudio y análisis de la evolución de los estudiantes matriculados en } \\
\text { titulaciones de Educación Musical en la Universidad Autónoma de Madrid } \\
\text { (Revista Electrónica de LEEME) Número } 47 \text {, pp. 17-38 } \\
\frac{\text { https://ojs.uv.es/index.php/LEEME/index }}{\text { DOI: 10.7203/LEEME.47.18295 }}\end{array}$} \\
\hline $\begin{array}{l}\text { Formación Musical } \\
\text { III: Formación } \\
\text { Vocal y Auditiva }\end{array}$ & $4^{\circ}$ & 6 & $1^{\circ}$ Semestre & OP \\
\hline $\begin{array}{l}\text { Formación Musical } \\
\text { IV: Composición } \\
\text { para la Escuela }\end{array}$ & $4^{\circ}$ & 6 & $1^{\circ}$ Semestre & $\mathrm{OP}$ \\
\hline $\begin{array}{l}\text { Formación Musical } \\
\text { V: Nuevas } \\
\text { Tecnologías } \\
\text { Aplicadas a la } \\
\text { Educación }\end{array}$ & $4^{\circ}$ & 6 & $1^{\circ}$ Semestre & OP \\
\hline $\begin{array}{c}\text { Prácticum de } \\
\text { Mención en } \\
\text { Educación Musical }\end{array}$ & $4^{\circ}$ & 12 & $2^{\circ}$ Semestre & OB \\
\hline
\end{tabular}

Fuente: datos procedentes de la Resolución de 17 de diciembre de 2012, por la que se publica la modificación del plan de estudios de Graduado en Magisterio en Educación Infantil

Los datos muestran que los créditos dedicados específicamente a la formación musical del profesorado han pasado de 74 créditos en la Diplomatura a 33 ECTS en la Mención en Educación Musical en Primaria y a 42 ECTS en la Mención en Educación Musical en Infantil. En el Prácticum es más llamativo el descenso, ya que cambió de 32 ECTS en el caso de la Diplomatura, a 12 ECTS en el caso de la Música en Primaria y a 9 ECTS en la Mención en Infantil. El título de Magisterio pasó a ser un Grado, como el resto de las titulaciones, y a incrementar el tiempo de duración de tres a cuatro años. Con el cambio, la especialidad de Música ha sido desfavorecida debido a la pérdida de ECTS de la materia en el plan de estudios actual y, por ende, su proyección formativa para los interesados en cursar esta especialidad (véase la Tabla $5)$.

Tabla 5. Comparativa del número de ECTS en la Diplomatura y en las Menciones en la Universidad Autónoma de Madrid

\begin{tabular}{ccc}
\hline $\begin{array}{c}\text { DIPLOMATURA MAESTRO EN } \\
\text { EDUCACIÓN MUSICAL }\end{array}$ & $\begin{array}{c}\text { MENCIÓN EN MÚSICA EN } \\
\text { EDUCACIÓN PRIMARIA }\end{array}$ & $\begin{array}{c}\text { MENCIÓN EN MÚSICA EN } \\
\text { EDUCACIÓN INFANTIL }\end{array}$ \\
\hline 74 ECTS & 33 ECTS & 42 ECTS \\
PRÁCTICUM 32 ECTS & PRÁCTICUM 12 ECTS & PRÁCTICUM 9 ECTS \\
\hline
\end{tabular}

Fuente: elaborada a partir de datos de Morales (2008) 


\section{c) La situación en la antigua Diplomatura de Maestro en Educación Musical}

En el presente estudio, se han recogido los datos desde los cursos 1997/1998 hasta 2005/2006, que contemplaban los planes de estudio de $1993^{5}$ y del $2000 .^{6}$

Como se muestra en la Tabla 6, las estadísticas muestran una tendencia al alza en el número de matrículas de nuevo ingreso en la especialidad musical desde el curso 1997/1998, alcanzando la significativa cifra de 84 estudiantes en el curso 2003/2004.

Tabla 6. Número de estudiantes de nuevo ingreso en la especialidad de Música

\begin{tabular}{|c|c|c|c|c|}
\hline CURSO & $\begin{array}{l}\text { PLAN DE } \\
\text { ESTUDIOS }\end{array}$ & $\begin{array}{c}\mathbf{N}^{\circ} \\
\text { ESTUDIANTES } \\
\text { DE NUEVO } \\
\text { INGRESO EN } \\
\text { ESPECIALIDAD } \\
\text { MÚSICA }\end{array}$ & $\begin{array}{c}\% \text { DE ESTUDIANTES } \\
\text { EN LA ESPECIALIDAD } \\
\text { DE MÚSICA SOBRE EL } \\
\text { TOTAL DE } \\
\text { ESTUDIANTES EN } \\
\text { ESPECIALIDADES }\end{array}$ & $\begin{array}{c}\% \text { DE ESTUDIANTES } \\
\text { MATRICULADOS EN } \\
\text { ESPECIALIDADES } \\
\text { SOBRE EL TOTAL DE } \\
\text { ESTUDIANTES } \\
\text { MATRICULADOS EN } \\
\text { LAS DIPLOMATURAS } \\
\text { DE MAESTRO }\end{array}$ \\
\hline $1997 / 1998$ & 1993 & 56 & 7,1 & 36,6 \\
\hline 1998/1999 & 1993 & 70 & 2,9 & 38,3 \\
\hline $1999 / 2000$ & 1993 & 70 & 10 & 46,9 \\
\hline $2000 / 2001$ & 2000 & 66 & 6,1 & 51 \\
\hline $2001 / 2002$ & 2000 & 79 & 19 & 53 \\
\hline $2002 / 2003$ & 2000 & 76 & 22,4 & 54 \\
\hline $2003 / 2004$ & 2000 & 84 & 22,6 & 36,6 \\
\hline $2004 / 2005$ & 2000 & 82 & 18,3 & 38,3 \\
\hline $2005 / 2006$ & 2000 & 85 & 18,8 & 46,9 \\
\hline
\end{tabular}

Fuente: datos procedentes de la Secretaría de la Universidad Autónoma de Madrid

\footnotetext{
${ }^{5}$ Ley Orgánica 1/1990, de 3 de octubre, de Ordenación General del Sistema Educativo; Real Decreto 1440/1991, de 30 de agosto, por el que se establece el título universitario oficial de Maestro en sus diversas especialidades y las directrices generales propias de los planes de estudios conducentes a su obtención; Resolución de 10 de diciembre de 1992, de la Universidad Autónoma de Madrid, por la que se ordena la publicación del plan de estudios de la Diplomatura Maestro-Educación Primaria y Resolución de 10 de diciembre de 1992, de la Universidad Autónoma de Madrid, por la que se ordena la publicación del plan de estudios de la Diplomatura Maestro-Educación Infantil.

${ }^{6}$ Resolución de 6 de junio de 2000, de la Universidad Autónoma de Madrid, por la que se acuerda la publicación de la adaptación del plan de estudios de Maestro, Especialidad de Educación Primaria, homologado por la Comisión Académica del Consejo de Universidades de fecha 21 de julio de 1992 y la Resolución de 6 de febrero de 2001, de la Universidad Autónoma de Madrid, por la que se acuerda la publicación de la adaptación del Plan de Estudios de Maestro, Especialidad Educación Infantil.
} 

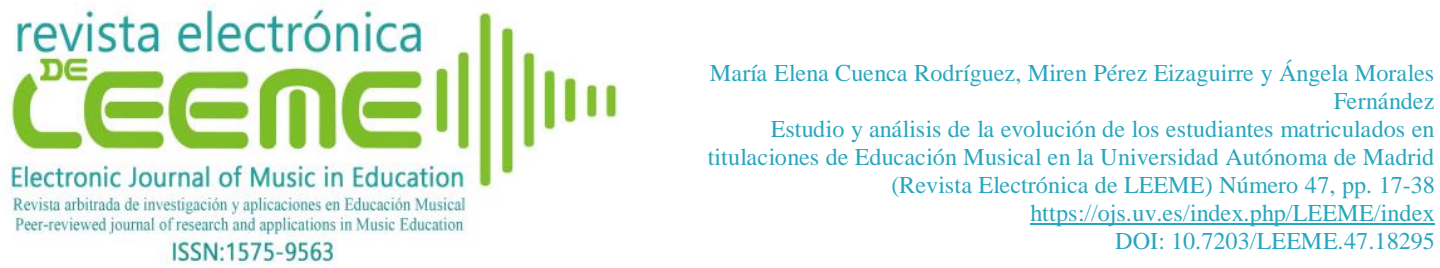

En la Tabla 6, también se muestra cómo el porcentaje de estudiantes matriculados en la especialidad de Música fue variando sobre el total de matriculados en las distintas especialidades que ofrecía la Facultad. El curso 2001/2002 supuso un cambio notable para la especialidad musical debido al incremento de discentes matriculados sobre las demás especialidades (Audición y Lenguaje, Educación Especial y Lengua Extranjera). Los valores porcentuales del alumnado matriculado en estas especialidades sobre el total de los matriculados en las diplomaturas de Magisterio han ido elevándose hasta alcanzar más de la mitad de los matriculados entre los cursos 2000 y 2003, coincidiendo con la adaptación del plan de estudios de Maestro en Educación Primaria y Maestro en Educación Infantil. Seguidamente, se dio un descenso en el curso siguiente, sin algún aparente motivo que lo justifique, para luego volver a valores al alza.

Para complementar esta información, puede observarse en la Tabla 6 y en la Figura 1 una tendencia alcista de la corriente de docentes especialistas sobre los generalistas. Esto es debido a que, desde el curso 1997/1998, se incrementó considerablemente el porcentaje de estudiantes matriculados en las distintas especialidades de la Diplomatura de Maestro en detrimento de aquellos que escogían los estudios genéricos de Infantil y Primaria. También, hay que tener en cuenta que en el curso 2002/2003 se añadieron las Diplomaturas de Maestro en Audición y Lenguaje y en Educación Especial y esto supuso un aumento significativo del porcentaje con respecto a los años anteriores.

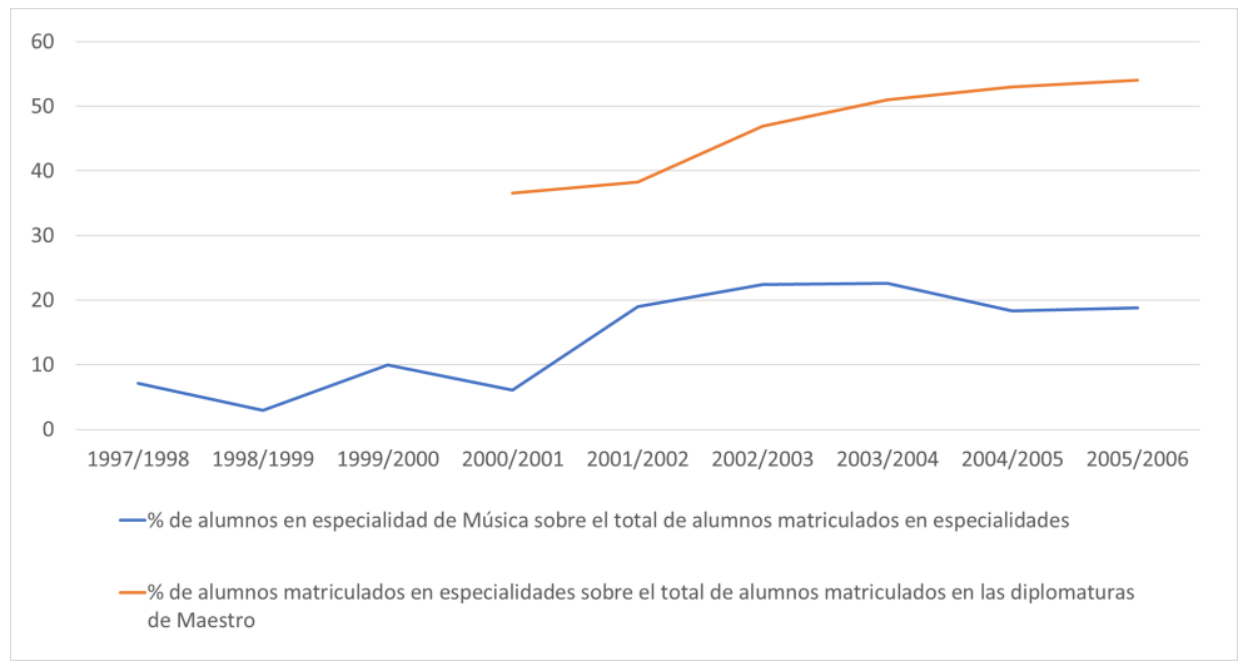

Figura 1. Porcentajes de estudiantes matriculados en la especialidad de Música y en otras especialidades de la diplomatura. Fuente: datos procedentes de los Anuarios completos de la Universidad Autónoma de Madrid (2020)

La última pregunta que cabe formular en este apartado es acerca de la preferencia de matriculación por las distintas especialidades en la antigua Diplomatura de Maestro en Educación. 

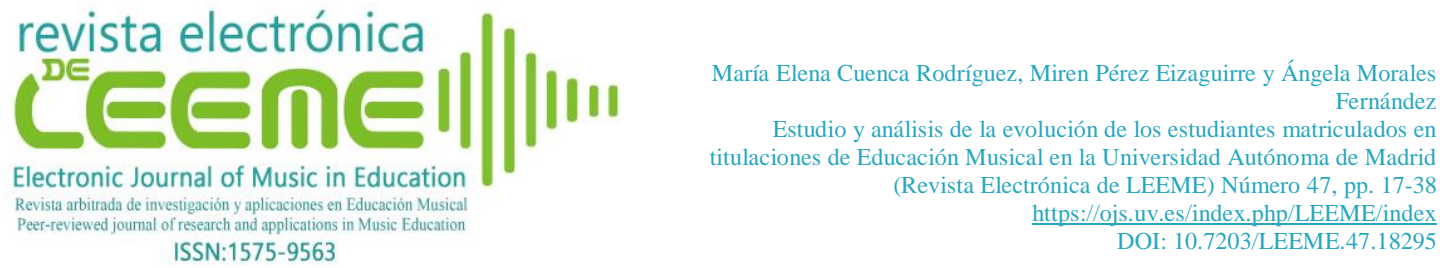

ISSN:1575-9563

La Figura 2 muestra que la Educación Musical comenzó y continuó siendo la más demandada en la Diplomatura del plan 1993, seguida por la especialidad de Educación Física. A partir del curso 2002/2003, año en el que también se implantaron las especialidades de Audición y Lenguaje y Educación Especial, la especialidad de Educación Física superó a la especialidad de Educación Musical. Desde ese curso, los valores de discentes matriculados han ido disminuyendo en todas las especialidades progresivamente hasta el 2005/2006, debido a una equiparación del número de estudiantes matriculados en todas ellas. En este último curso, la Educación Musical presentaba una tendencia al alza.

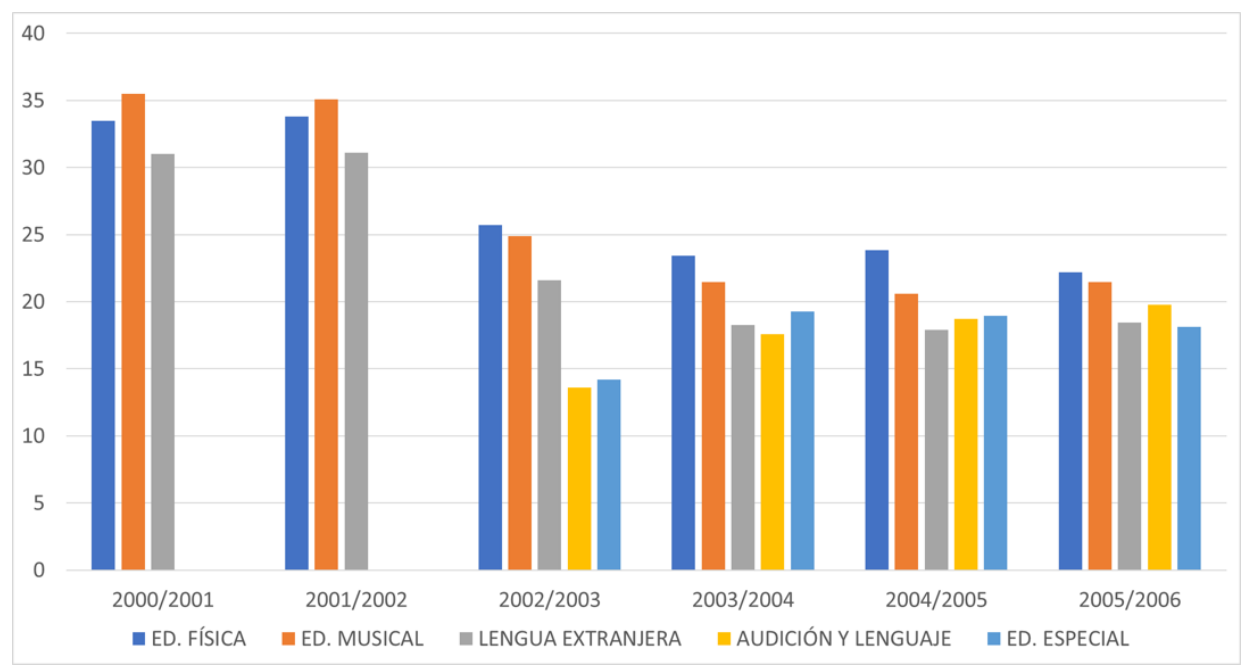

Figura 2. Porcentaje de estudiantes matriculados en las distintas especialidades sobre el total de matriculados en todas las especialidades de la antigua Diplomatura. Fuente: datos procedentes de los Anuarios completos de la Universidad Autónoma de Madrid (2020)

\section{d) Comparativa entre los planes de 1993 y 2007}

Para comparar los datos de la actual Mención en Educación Musical con los antiguos planes de estudios de la especialidad musical, se ha empezado por el curso 2011/2012 hasta el actual curso de 2019/2020. Se excluye el salto entre los cursos 2006/2007 hasta 2011/2012, ya que en este periodo comenzaron a implementarse los nuevos Grados de Maestro en Educación Infantil y Educación Primaria, mientras se extinguía la antigua Diplomatura, y no existían cifras sobre los matriculados en las distintas menciones hasta el sobredicho curso 2011/2012. El plan de 2000 ha sido excluido de nuestro estudio al no aportar ninguna información significativa en la comparación. 
Tabla 7. Número de discentes matriculados en la diplomatura de Maestro en Educación Musical y en las menciones de Música del grado sobre el total de discentes matriculados

\begin{tabular}{|c|c|c|c|c|}
\hline $\begin{array}{c}\text { Curso de } \\
\text { Diplomatura }\end{array}$ & $\begin{array}{c}\mathrm{N}^{\mathrm{o}} \text { de discentes } \\
\text { matriculados en } \\
\text { Diplomatura Maestro } \\
\text { Educación Musical } \\
\text { sobre el total de } \\
\text { matriculados en } \\
\text { especialidades }\end{array}$ & $\begin{array}{l}\text { Curso de } \\
\text { Grado }\end{array}$ & $\begin{array}{c}\mathrm{N}^{\mathrm{o}} \text { de discentes } \\
\text { matriculados en la } \\
\text { Mención de Música del } \\
\text { Grado Maestro } \\
\text { Educación Primaria } \\
\text { sobre el total de } \\
\text { matriculados }\end{array}$ & $\begin{array}{c}\mathrm{N}^{\mathrm{o}} \text { de discentes } \\
\text { matriculados en la } \\
\text { Mención de Música del } \\
\text { Grado Maestro } \\
\text { Educación Infantil sobre } \\
\text { el total de matriculados }\end{array}$ \\
\hline- & - & $2012 / 2013$ & $68 / 1217(6 \%)$ & $300 / 874(34 \%)$ \\
\hline- & - & $2013 / 2014$ & $47 / 1250(4 \%)$ & $256 / 888(29 \%)$ \\
\hline $2000 / 2001$ & $241 / 679(35 \%)$ & $2014 / 2015$ & $34 / 1243(3 \%)$ & $187 / 916(20 \%)$ \\
\hline $2001 / 2002$ & $244 / 695(35 \%)$ & $2015 / 2016$ & $0 / 1233(0 \%)$ & $229 / 918(25 \%)$ \\
\hline $2002 / 2003$ & $247 / 992(24 \%)$ & $2016 / 2017$ & $88 / 1172(8 \%)$ & $216 / 871(25 \%)$ \\
\hline $2003 / 2004$ & $248 / 1156(21 \%)$ & $2017 / 2018$ & $74 / 1133(7 \%)$ & $239 / 832(29 \%)$ \\
\hline $2004 / 2005$ & $262 / 1272(20 \%)$ & $2018 / 2019$ & $79 / 1028(8 \%)$ & $240 / 806(30 \%)$ \\
\hline $2005 / 2006$ & $284 / 1324(21 \%)$ & $2019 / 2020$ & $49 / 929(5 \%)$ & $158 / 770(21 \%)$ \\
\hline
\end{tabular}

Fuente: datos procedentes de los anuarios completos (Universidad Autónoma de Madrid, 2020)

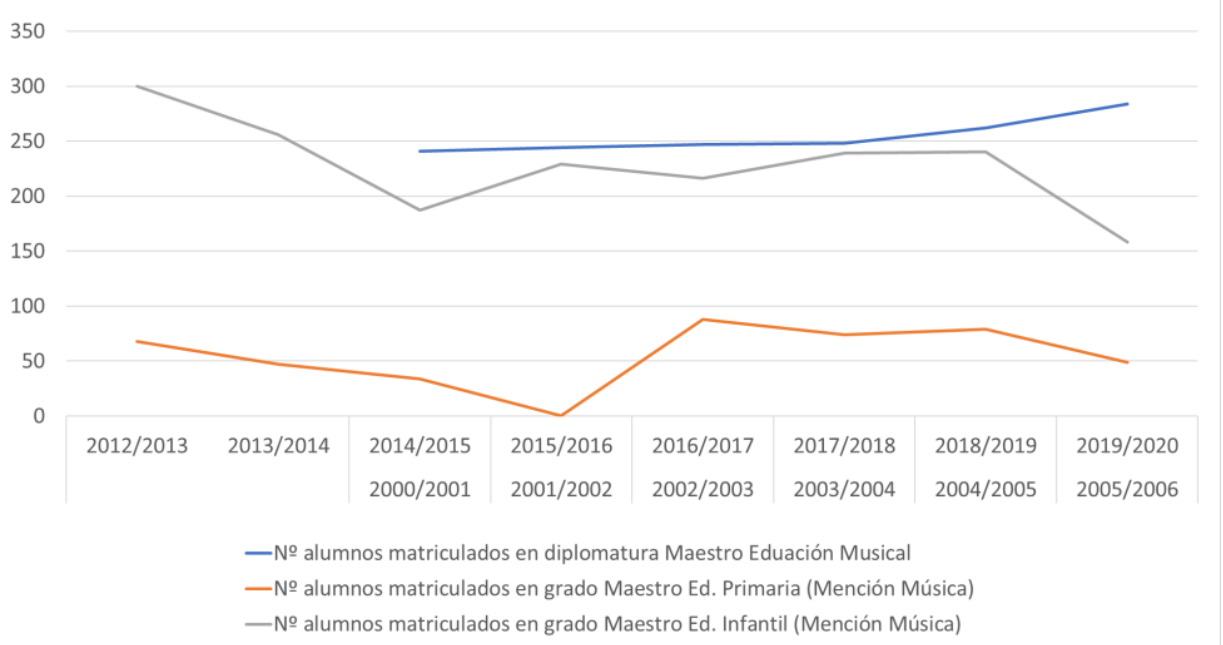

Figura 3. Porcentaje de estudiantes matriculados en las distintas especialidades sobre el total de matriculados en todas las especialidades de la antigua Diplomatura. Fuente: datos procedentes de los Anuarios completos de la Universidad Autónoma de Madrid (2020)

En la Tabla 7 y la Figura 3, puede observarse cómo el número de matriculados es radicalmente superior en la antigua especialidad musical con respecto a los matriculados en la Mención en Educación Musical del Grado de Primaria. De hecho, en esta se produjo una cancelación en la oferta de esta mención en el curso 2015/2016 (de ahí la caída al 0), debido a la 
baja tasa de matriculaciones en el curso anterior 2014/2015. El siguiente curso se volvió a elevar a 88 estudiantes ante el patrocinio de esta mención por parte del Departamento de Música. También, se observa que la tendencia general de la Mención en Educación Musical en Primaria es descendente, mientras que el alumnado en la antigua Diplomatura aumentaba progresivamente hasta los últimos años. En ese último curso 2005/2006, la cifra de matriculados en la especialidad musical del plan 1993 era 284 discentes, mientras que en el último curso de la Mención en Educación Musical en Primaria descendía a 49.

No obstante, si se observan los porcentajes de matriculación en la especialidad musical sobre el total de estudiantes matriculados en todas las especialidades, se muestra que los interesados en la primera fueron disminuyendo hasta porcentajes del $20 \%$ entre los años 2003 y 2006. Este hecho, como se ha comentado anteriormente en la Figura 2, se debe a un mayor interés por la especialidad de Educación Física y a una mayor oferta con las nuevas especialidades de Audición y Lenguaje y Educación Especial.

En el caso de la Mención en Educación Musical en Infantil, esta situación se modifica sustancialmente. Desde que se creó dicha mención para esta etapa educativa, la música ha sido bastante demandada por el alumnado de Infantil. No obstante, aunque la Música en Infantil se ha mantenido con valores bastante altos en la matriculación -superando casi siempre los 200 estudiantes matriculados-, en el curso 2019/2020 se ha producido un descenso considerable a 158 matriculados.

Por tanto, si se compara la situación actual con la de la antigua Diplomatura, se observa una caída abismal en el interés por cursar la Mención en Educación Musical, contradictoriamente, más pronunciada en el Grado de Educación Primaria - siendo una mención profesionalizanteque en el de Infantil. Mientras que en el plan de 1993 la tendencia mayoritaria ha sido hacia la formación de especialistas, en el nuevo plan Bolonia abogan más por un perfil de docente generalista. Además, en términos globales, en la Tabla 7 se muestra cómo el número de estudiantes matriculados en las especialidades fue creciendo paulatinamente a lo largo de los años, mientras el número de matriculaciones disminuye considerablemente en el Grado de Educación Primaria y ligeramente en el Grado de Educación Infantil. Este hecho podría responder a muchas circunstancias externas, pero ante todo desvela cómo el plan de 1993 tuvo más éxito en términos numéricos frente a los nuevos grados del plan Bolonia, cuya demanda por parte del estudiantado se ha reducido significativamente. 


\section{e) La Mención en Educación Musical en el contexto del resto de menciones de la Facultad}

Dentro de los datos extraídos desde los últimos cursos hasta la actualidad, se realizaron dos análisis distintos en los que contrastamos las distintas menciones, tanto en el Grado de Maestro en Educación Primaria como en el de Maestro en Educación Infantil.

\section{Comparativa entre menciones en el Grado de Maestro en Educación Primaria}

A continuación, se expone una gráfica que desvela la situación entre las distintas menciones en el Grado de Maestro en Educación Primaria, basada en el número de estudiantes matriculados en cada mención (Figura 4) y donde la línea marrón horizontal representa la evolución del total de estudiantes matriculados en menciones. Puede observarse cómo la Mención en Educación Musical comenzó con valores de 68 estudiantes matriculados en el curso 2012/2013 y bajó hasta no contar con estudiantes en el curso 2015/2016 -ya que se canceló la oferta de dicha mención en ese curso debido a la baja tasa de estudiantes en el anterior-.

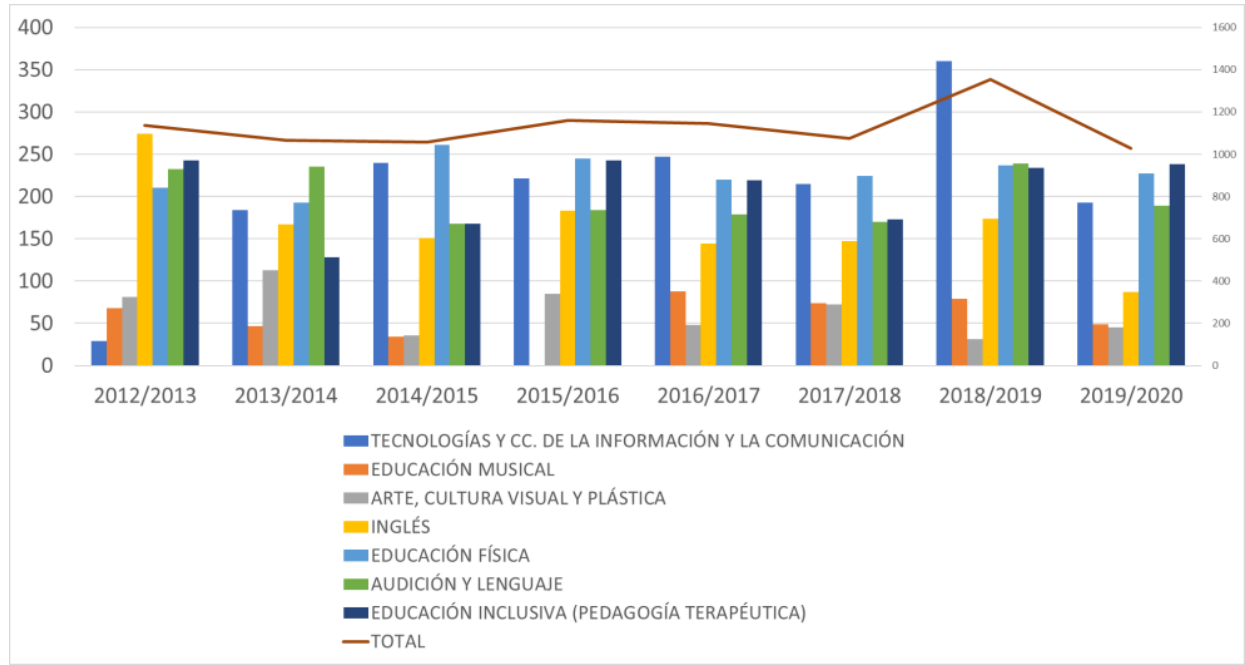

Figura 4. Número de estudiantes matriculados en las distintas menciones de Primaria. Fuente: datos procedentes de los Anuarios completos de Universidad Autónoma de Madrid (2020)

Posteriormente, se elevó a 88 discentes en el curso 2016/2017 para disminuir paulatinamente hasta el actual curso 2019/2020, con 49 estudiantes matriculados. Si se comparan estos datos con la evolución del número total que escoge la especialización en el Grado, se muestran leves disminuciones en las matrículas en los cursos 2014/2015 y 2017/2018. Si además se observan las cifras de matriculaciones en el Grado de Primaria, como se ha dicho 

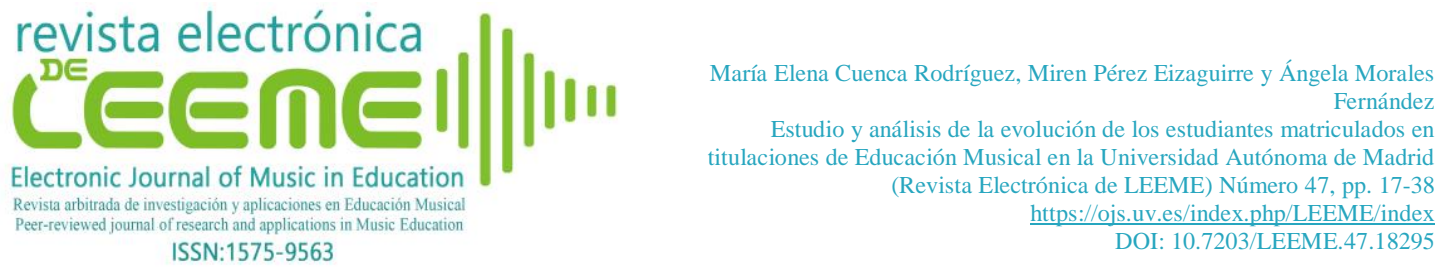

anteriormente, se produce un descenso paulatino que afectaría disminuyendo la matriculación en todas las menciones (Tabla 7).

Por otro lado, probablemente como consecuencia de la cancelación de la mención de Música y en el curso 2015/2016, las demás menciones muestran un aumento sustancial. En el curso 2018/2019, mientras la mención en Tecnologías y Ciencias de la Información y la Comunicación repunta significativamente, la mención en Arte, Cultura Visual y Plástica baja a sus valores mínimos y la mención en Educación Musical se vuelve a consolidar en torno al 8\% de estudiantes sobre el total de matriculados en el grado (Tabla 7).

Como puede observarse también en la Figura 5, las menciones más solicitadas en Primaria son Tecnologías y Ciencias de la Información y la Comunicación, Educación Física y Educación Inclusiva, siguiéndole Audición y Lenguaje e Inglés. Sin embargo, las menciones artísticas (Educación Musical y Arte, Cultura visual y Plástica) no están tan demandadas y suelen tener una tasa de matriculación bastante baja en algunos cursos.

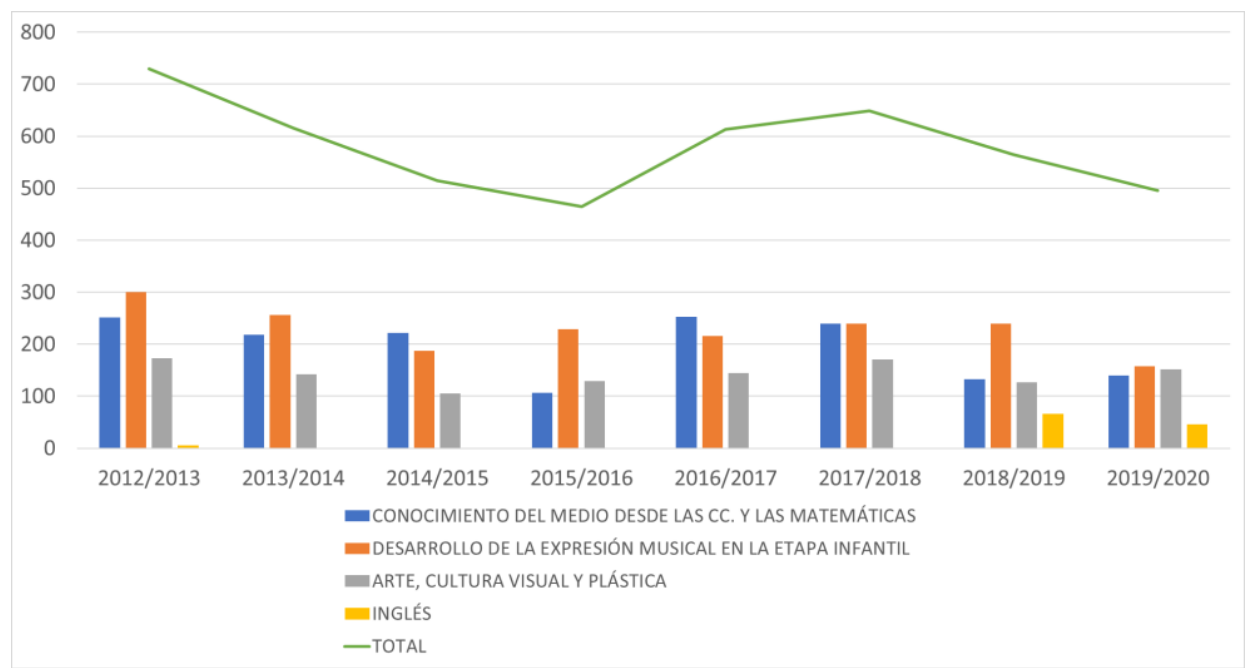

Figura 5. Número de estudiantes matriculados en las distintas menciones de Infantil. Fuente: datos procedentes de los anuarios completos de Universidad Autónoma de Madrid (2020)

\section{Comparativa entre menciones en el Grado de Maestro en Educación Infantil}

El panorama se transforma cuando se trata del caso de Educación Infantil. En este sentido, el Desarrollo de la Expresión Musical es una de las menciones más solicitadas por el alumnado, según los datos obtenidos (Tabla 7). Además, mientras se mostraba cómo el número de matriculados en el Grado se incrementa y luego decae, el porcentaje de inscritos en la Mención Musical se mantiene entre valores del $20 \%$ y el $30 \%$, lo que refleja un interés mantenido por esta.

@ María Elena Cuenca Rodríguez, Miren Pérez Eizaguirre y Ángela Morales Fernández. The content of this article is the sole responsibility of the authors. The Revista Electrónica de LEEME and Universitat de València are not liable for any legal actions that may arise involving the article's content. Revista Electrónica de LEEME - Lista Electrónica Europea de Música en la Educación-. http://ojs.uv.es/index/php/LEEME/index ISSN: 1575-9563. Editores: Universidad de Valencia y Jesús Tejada. Visibilidad de esta revista: SCOPUS, Emerging Sources Citation Index (Clarivate), EBSCO, CINDOC (CSIC), Citefactor, COPAC, Dialnet, DICE (CSIC), DOAJ, e-revistas (CSIC), EBSCO Premier, ERIH+, Gale Cengage Learning, IN-RECS, IRESIE, LATINDEX, MIAR, OCLC Worldcat, RESH, REDIB, RILM Core Journals, SUDOC, ULRICHS. Esta revista es de acceso libre mediante licencia Creative Commons 4.0 CC by. Política de archivado: etiqueta verde SHERPA-ROMEO. 
Si se contrastan estos datos con los valores totales de matriculados en menciones (línea verde de la Figura 5), se observa que la tendencia total de estudiantes matriculados en menciones disminuye considerablemente en el curso 2015/2016. En este curso existe un mayor número de estudiantes matriculados en el Grado de Infantil (Tabla 7). Este hecho puede indicar una predilección por el modelo de docente generalista en esta etapa educativa. Sin embargo, también se muestra un pequeño repunte en los cursos 2016 a 2018 y una caída en los últimos cursos 2018/2019 y 2019/2020, debido a un descenso en la tasa de matriculación general del Grado (Tabla 7).

Si se analiza la demanda de cada mención, se desvela que Desarrollo de la Expresión Musical en la etapa de Infantil es una de las más solicitadas, por encima, casi siempre, de Conocimiento del Medio desde las Ciencias y las Matemáticas. La mención de Desarrollo de la Expresión Musical en la etapa de Infantil llega hasta el 49\% de estudiantes matriculados sobre el total de matriculados en menciones.

Claramente, la situación difiere considerablemente entre los distintos grados de Maestro: mientras, en Educación Primaria, la Educación Musical es una de las menciones menos demandadas por el alumnado - que siente mayor predilección por menciones como Tecnología y Ciencias de la Información y la Comunicación, Educación Física o Educación Inclusiva-, en Educación Infantil se convierte en la intensificación curricular preferente.

\section{Discusión y conclusiones}

Nuestro estudio ha mostrado que la preferencia del estudiantado por la especialización musical ha decaído considerablemente con el cambio del plan de 1993 al de 2007. Esto puede deberse a varios motivos: uno puede deberse al cambio sustancial en el plan de estudios de Primaria (mientras antes había 65 créditos para las materias de Música, actualmente solo cuentan con 27 ECTS más el prácticum que se incluye en la mención); otro puede obedecer a las diferentes tendencias hacia modelos más especialistas (plan de 1993) o generalistas (plan de 2007). A pesar de esto, podría señalarse como un avance positivo la aparición de la Mención en Educación Musical en Infantil. Autores como López de la Calle (2008) se hicieron eco en su día de la insuficiente formación musical en el Grado de Maestro en Educación Infantil en las universidades gallegas al no alcanzar los mínimos exigibles para la adecuación de la titulación al Espacio Europeo de Educación Superior. Este hecho podría conllevar una complicación a la hora de impartir la asignatura de Música de manera adecuada al incorporarse a los centros de Educación Infantil. Era necesaria la especialización del futuro profesorado de Música de esta etapa.

Por otro lado, en el Grado de Primaria, la Mención de Educación Musical contempla unos valores muy bajos de matriculación con respecto a la antigua Diplomatura. Las menciones más 
populares y demandadas por el alumnado del Grado de Primaria son las relacionadas con la Tecnología y Ciencias de la Información y la Comunicación (no es profesional) ${ }^{7}$, Educación Física, Audición y Lenguaje y Educación Inclusiva. Estas últimas ya venían mostrando valores bastante altos en la antigua Diplomatura. Todas ellas son menciones que no precisan de conocimientos técnicos previos, como ocurre con la Mención de Educación Musical.

Contradictoriamente, existe un mayor interés por la música en Infantil -cuya mención no es profesional- y no tanto en Primaria, a pesar de que, en este, la mención sí habilita la docencia de esta asignatura al igual que la tarea del especialista. Los valores altos de matriculación en la Mención en Educación Musical en Infantil podrían deberse a una menor oferta de menciones en este Grado en comparación con el de Primaria (que tiene hasta siete menciones distintas, en comparación con las cuatro menciones en Infantil) y a la doble disponibilidad de la Mención en Educación Musical en turno de mañana y de tarde.

Otros motivos de esta preferencia se esgrimen en investigaciones como la de García-Gil y Bernabé (2019), donde se expone en los relatos de las alumnas del Grado de Educación Infantil la importancia del hecho musical siendo un elemento muy cotidiano y presente en el alumnado de esta etapa. Destacan también la combinación del contenido de otras materias con la parte lúdica que conlleva la música y, además, señalan que la impartición de esta asignatura en Educación Infantil fija el aprendizaje para etapas posteriores (García-Gil y Bernabé, 2019). Podría considerarse un motivo también de peso a la hora de decantarse por la Mención en Educación Musical en Infantil en mayor medida que por la Mención en Educación Musical en Primaria.

En definitiva, desconocemos muchas de las causas por las cuales se ha producido un descenso de la matriculación de estudiantes en las menciones de Música de la Universidad Autónoma de Madrid. Aquí podrían retomarse las diferentes posiciones controvertidas (Vilar, 2003) que abogan por el profesorado especialista (Montesinos, 2011) o por el profesorado generalista (Aróstegui, 2006; Aróstegui, 2013; Aróstegui y Cisneros-Cohernour, 2010;). Otros autores proponen soluciones intermedias. Por ejemplo, Cremades-Andreu y García-Gil (2017) señalan que la formación musical del profesorado generalista debería incrementarse y plantean la realización de cursos de especialización para completar la capacitación musical de los futuros maestros de Primaria, a través de los cuales se pudiese certificar una Educación Musical de calidad que ayudara al alumnado de esta etapa a aproximarse a la música y a disfrutarla. En esta misma línea, Esteve et al. (2013) evaluaron si la asignación de tiempo propuesta en la Guía de Estudios Musicales, adaptada de las directrices del Espacio Europeo de Educación Superior, resultaba coherente y adecuada para el estudiantado con conocimientos musicales mínimos. Los resultados mostraron que el alumnado que se matriculara en la universidad sin ningún

\footnotetext{
${ }^{7}$ Es decir, que habilita a la profesión de docente especializado en una materia concreta de Educación Primaria, como puede ser, Música o Educación Física.
} 
conocimiento musical previo probablemente experimentaría una dificultad significativa en la adquisición de determinadas competencias musicales y profesionales. La solución propuesta por los autores contempla reforzar el plan de estudios de música o establecer cursos de nivel cero, a fin de que esos estudiantes pudieran tener éxito en la asignatura.

Se puede reflexionar sobre si el alumnado que tiene conocimientos musicales se decanta por otras opciones universitarias en las que hay mayor contenido en relación con la música. Cuando existía el Título de Maestro, Especialidad de Educación Musical, la tendencia a realizar los estudios de Magisterio era mayor que en la actualidad, por lo que quizás para un alumnado más especializado de partida no sea suficiente la carga lectiva que presentan las menciones cualificadoras. En contraposición, para un alumnado sin conocimientos musicales puede resultar complejo cursar estas menciones. Buscar soluciones intermedias y adecuadas a todo el estudiantado como las propuestas por los autores y autoras que se han mencionado en este artículo, podría ser una salida factible.

\section{Compromiso ético}

Las autoras declaran que se han seguido los procedimientos conformes a las normas éticas institucionales, locales y nacionales y que no hay conflicto de intereses personales o colectivos que puedan influir en los resultados obtenidos.

\section{Referencias}

Aróstegui, J.L. (2006). La Formación del Profesorado en Educación Musical ante la Convergencia Europea en Enseñanzas Universitarias. Revista de Educación, 341, 829-844. Recuperado de: https://dialnet.unirioja.es/servlet/articulo?codigo=2165335

Aróstegui, J.L. y Cisneros-Cohernour, E. (2010). Reflexiones en torno a la formación del profesorado de música a partir del análisis documental de los planes de estudio en Europa y América Latina. Profesorado. Revista de Currículum y Formación de Profesorado, 14(2), 179-189. Recuperado de: https://recyt.fecyt.es/index.php/profesorado/article/view

Aróstegui, J.L. (2013). El desarrollo de la identidad profesional del profesorado: el caso del especialista de música. Revista Interuniversitaria de Formación Del Profesorado, 27(3), 145-159. Recuperado de: https://dialnet.unirioja.es/descarga/articulo/4688524.pdf

Aróstegui, J.L., Louro, A.L. y de Oliveira Teixeira, Z.L. (2015). Las políticas educativas de reforma y su impacto en la Educación Musical Escolar. De dónde venimos y hacia dónde podemos ir. Revista da ABEM, 23(35), 24-34. Recuperado de: http://www.abemeducacaomusical.com.br/revistas/revistaabem/index.php/revistaabem 
Baena, M.P.L. (2007). Estudio comparado de los nuevos títulos de Grado de Educación Infantil en el Espacio Europeo de Educación Superior (EEES). Revista de Educación, 343, 275299. Recuperado de: https://dialnet.unirioja.es/servlet/articulo?codigo=2309658

Belletich, O., Ángel, R. y Wilhelmi, M. (2017). Normas epistémicas en la formación musical del maestro de educación primaria. Journal for Educators, Teachers and Trainers, 8(1), 199213. Recuperado de: https://academica-e.unavarra.es/bitstream/handle/2454/32427/

Carbajo Martínez, C. (2009). El perfil profesional del docente de música de educación primaria: autopercepción de competencias profesionales y la práctica de aula. (Tesis doctoral). Murcia: Universidad de Murcia.

Casanova, O. y Serrano, R. (2018). La Educación Musical en el actual currículo español. ¿Qué formación recibe el alumnado en la enseñanza Primaria? Revista Electrónica Complutense de Investigación en Educación Musical, 15, 3-17. doi:10.5209/RECIEM.54844

Consejería de Presidencia Comunidad de Madrid (2014). Resolución de 6 de junio de 2014, de la Universidad Autónoma de Madrid, por la que se publica la modificación del plan de estudios de Graduado en Magisterio en Educación Infantil. BOE (26/06/2014), núm.155, pp.49394-49400.

Consejo de Universidades (1993). Resolución de 10 de diciembre de 1992, de la Universidad Autónoma de Madrid, por la que se ordena la publicación del plan de estudios de la Diplomatura Maestro-Educación Primaria. BOE (04/02/1993), núm.30, referencia 3071, pp.3263-3278.

Consejo de Universidades (1993). Resolución de 10 de diciembre de 1992, de la Universidad Autónoma de Madrid, por la que se ordena la publicación del plan de estudios de la Diplomatura Maestro-Educación Infantil. BOE (05/02/1993), núm.31, referencia 3071, pp.3465-3481.

Consejo de Universidades (2000). Resolución, de 6 de junio de 2000, de la Universidad Autónoma de Madrid, por la que se acuerda la publicación de la adaptación del plan de estudios de Maestro, Especialidad de Educación Musical, homologado por la Comisión Académica del Consejo de Universidades de fecha 21 de julio de 1992. BOE (26/06/2000), núm.152, referencia 11989, pp.22560-22572.

Consejo de Universidades (2000). Resolución de 6 de junio de 2000, de la Universidad Autónoma de Madrid, por la que se acuerda la publicación de la adaptación del plan de estudios de Maestro, Especialidad de Educación Primaria, homologado por la Comisión 

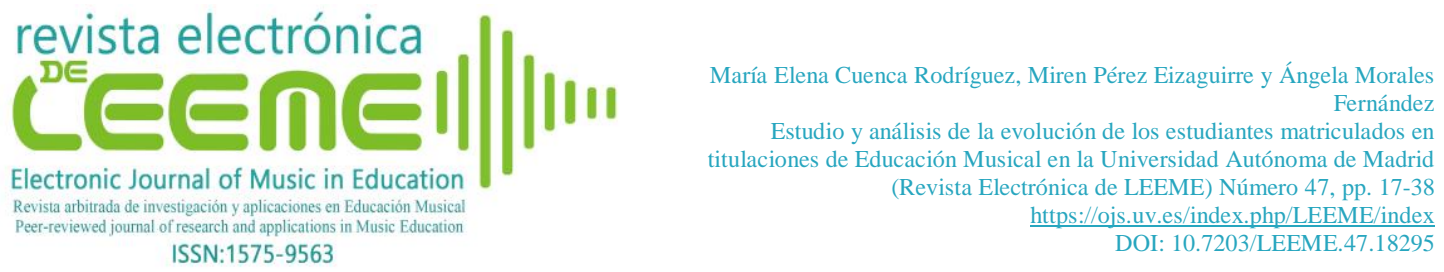

Académica del Consejo de Universidades de fecha 21 de julio de 1992. BOE (26/07/2000), núm.152, referencia 11992, pp.22586-22598.

Consejo de Universidades (2001). Resolución de 6 de febrero de 2001, de la Universidad Autónoma de Madrid, por la que se acuerda la publicación de la adaptación del Plan de Estudios de Maestro, Especialidad Educación Infantil. BOE (01/03/2001), núm.52, referencia 4181, pp.7803-7822.

Consejo de Universidades (2012). Resolución de 17 de diciembre de 2012, de la Universidad Autónoma de Madrid, por la que se publica la modificación del plan de estudios de Graduado en Magisterio en Educación Primaria. BOE (29/12/2012), núm.313, referencia 15750, pp.89531-89535.

Cremades-Andreu, R. y García-Gil, D. (2017). Formación musical de los graduados de Maestro en Educación Primaria en el contexto madrileño. Revista Española de Pedagogía, 75(268), 415-431. doi:10.22550/REP75-3-2017-06

Díaz, M. (2005). La Educación Musical en la Escuela y el Espacio Europeo de Educación Musical. Revista Interuniversitaria de Formación del Profesorado, 19(1), 23-37. Recuperado de: https://dialnet.unirioja.es/servlet/articulo?codigo=1343153

Esteve, J.M., Espinosa, J.A., Molina, M.A. y López de Riego, C. (2006). Los Maestros en Educación Musical ante la convergencia europea. Música y Educación, 65, 181-202. Recuperado de: https://dialnet.unirioja.es/servlet/articulo?codigo=1421066

García-Gil, D. y Bernabé, M. (2019). Formación y preparación musical en el Grado de Educación Infantil: Consideraciones de las alumnas en Educación Superior. Prisma Social, 25, 126178. Recuperado de: https://dialnet.unirioja.es/servlet/articulo?codigo=6972161

Jefatura del Estado (1970). Ley 14/1970, de 4 de agosto, General de Educación y Financiamiento de la Reforma Educativa. BOE (06/08/1970), núm.187, pp.12525-12546.

Jefatura del Estado (1985). Ley Orgánica 8/1985, de 3 de julio, reguladora del Derecho a la Educación. BOE (04/07/1985), núm.159, referencia 12978, pp.21015-21022.

Jefatura del Estado (1990). Ley Orgánica 1/1990, de 3 de octubre, de Ordenación General del Sistema Educativo. BOE (04/10/1990), num.238, referencia 24172, pp.28927-28942.

Jefatura del Estado (2006). Ley Orgánica 2/2006, de 3 de mayo, de Educación. BOE (04/05/2006), núm.106, referencia 7899, pp.17158-17207. 
Jefatura del Estado (2013). Ley Orgánica 8/2013, de 9 de diciembre, para la mejora de la calidad educativa. BOE (10/12/2013), núm.295, referencia 12886, pp.97858-97921.

López de la Calle, M.D.A. (2008). La formación del maestro de Educación Infantil en la música y su enseñanza y su adecuación al Espacio Europeo de Educación Superior. Innovación Educativa, 18, 223-237. Recuperado de: https://minerva.usc.es/xmlui/

López García, N. (2015). Necesidades profesionales del profesorado especialista de música de los centros de educación primaria de Castilla-La Mancha. (Tesis doctoral no publicada). Málaga: Universidad de Málaga.

López García, N., Madrid, D. y de Moya, M.V. (2017). La formación musical en los planes de estudios para maestros de Primaria en la Universidad de Castilla-La Mancha. Estudios pedagógicos (Valdivia), 43(1), 423-438. doi:10.4067/S0718-07052017000100024

Maldonado, A. (2004). Los Títulos de Grado de Magisterio: El proceso de su diseño. Revista Interuniversitaria de Formación del Profesorado, 18(3), 43-59. Recuperado de: https://dialnet.unirioja.es/servlet/articulo?codigo $=1113359$

Ministerio de Educación y Ciencia (1991). Real Decreto 1440/1991, de 30 de agosto, por el que se establece el título universitario, oficial de Maestro, en sus diversas especialidades y las directrices generales propias de los planes de estudios conducentes a su obtención. BOE (11/10/1991), núm.244, referencia 24768, pp.33003-33018.

Ministerio de Educación y Ciencia (2007). Orden ECI/3857/2007, de 27 de diciembre, por la que se establecen los requisitos para la verificación de los títulos universitarios oficiales que habiliten para el ejercicio de la profesión de Maestro en Educación Primaria. BOE (29/12/2007), núm.312, referencia 22449, pp.3747-53750.

Ministerio de Educación y Ciencia (2007). Orden ECI/3854/2007, de 27 de diciembre, por la que se establecen los requisitos para la verificación de los títulos universitarios oficiales que habiliten para el ejercicio de la profesión de Maestro en Educación Infantil. BOE (29/12/2007), núm.312, referencia 22446, pp.3735-53738.

Montesinos, R. (2011). El maestro especialista: formación musical inicial y praxis de la Educación Musical escolar. (Tesis doctoral). La Laguna: Universidad de La Laguna, Servicio de Publicaciones.

Montero, M. (2010). El proceso de Bolonia y las nuevas competencias. Tejuelo, 9, 19-37. Recuperado de: https://dialnet.unirioja.es/servlet/articulo?codigo=3719324 
Morales, A. (2008). La Educación Musical en primaria durante la LOGSE en la Comunidad de Madrid: análisis y evaluación. (Tesis doctoral). Madrid: Universidad Autónoma de Madrid.

Ocaña, A. (2006). Desarrollo profesional de las maestras de Educación Musical desde una perspectiva biográfico-narrativa. Revista Electrónica Complutense de Investigación en Educación Musical-RECIEM, 3(3), 1-14. Recuperado de: https://revistas.ucm.es/index

Reyes, M.L. (2010). Evaluación de los planes de estudio de formación del profesorado de Educación Musical: España. Profesorado. Revista de Currículum y Formación de Profesorado, 14(2), 67-81. Recuperado de: https://dialnet.unirioja.es/servlet/articulo

Rodríguez, E., Navarro, H. y Rojo, M. (2010). La formación inicial de profesionales de la educación: un análisis crítico de los nuevos planes de estudio en el contexto del "capitalismo académico". Revista Interuniversitaria de Formación del Profesorado, 24(2), 151-174. Recuperado de: https://dialnet.unirioja.es/descarga/articulo/3276056.pdf

Touriñán, J.M. y Longueira, S. (2010). La música como ámbito de educación. Educación «por» la música y educación «para» la música. Teoría de la Educación. Revista Interuniversitaria, 22, 151-181. Recuperado de: https://dialnet.unirioja.es/servlet/articulo

Universidad Autónoma de Madrid (2020). Anuarios completos. Recuperado de: https://www.uam.es/UAM/Anuarios-Completos/1446756925135.htm

Vilar, M. (2003). El maestro de música en Primaria: enfoques y perspectivas. Música y Educación, 16(54), 33-56. Recuperado de: https://dialnet.unirioja.es/servlet/articulo 